\title{
Viewpoints
}

The Natural Resources Forum is running a special series over the 2007-2009 period on themes to be considered by the United Nations Commission on Sustainable Development in its $16^{\text {th }}$ and $17^{\text {th }}$ sessions: Africa, agriculture, desertification, drought, land and rural development. The Viewpoints in this issue will focus on the impact of growing demand for biofuels on food security.

\section{Experts address the question: \\ "Can the growing demand for biofuels be met without threatening food security?"}

Biofuels and food security: It all depends.

The production of biofuels involves too many variables to contain under a single umbrella term. Different feed stocks, objectives, marketing, required inputs, economics, and numerous other variables make any generalisations difficult. If the focus is on food security, then biofuels should be confined to providing local needs for energy that will enable greater food productivity. This might include growing biodiesel crops in parts of the landscape that are not being used for food crops, and locally processing the biodiesel to provide fuel for the agricultural machinery that enhances productivity and labour efficiency. Including some biofuel crops as part of diverse farming systems can help the rural poor to diversify their sources of income, thereby contributing to their food security. This requires specific government policies designed to ensure that the flow of benefits from biofuels is directed specifically at the rural poor.

We should also be looking ahead to more advanced technologies that will be able to produce biofuels without compromising food production. Some of these may involve technologies that are readily available to the rural poor. Replacing firewood and charcoal with more modern and efficient forms of biofuel may provide health benefits as well as improved food security. In short, biofuels definitely have the potential to enhance food security, but only if their production is specifically designed with this objective in mind.

\section{Jeffrey A. McNeely \\ Chief Scientist \\ IUCN (International Union for Conservation of Nature) Gland, Switzerland}

Biofuels by definition should come from plant biomass. However, this should not include that targeted to be consumed by humans, by animals that form part of the human diet, or needed to build up organic matter in (degraded) soils. Nevertheless, this leaves a huge variety of plants to choose from, leading to the need to assess the productivity and caloric value of the various plant species as to their potential to produce biofuel. But above all, there is a need to study the trade-off with the three primary demanding parties — food, feed and organic matter.

There are also questions of competition over land. Some people think that biofuel production should be practiced in the marginal and less fertile soils. But these lands are typically reserved for low intensity pasture, forage and livestock production, that provide sustenance to some of the poorest sectors (herders and pastoralists) in our society.

These issues beg the question as to whether some integration or complementarity might be achieved by intensifying the pasture production towards more efficient systems of management and/or integrating them with the use of land for biofuels and feeding the residues to animals. There is much scope for better organization and zoning of agricultural lands in the debate on where and how to grow plants for biofuels, with the human element always needing to be considered first.

Promoting the production of biofuel may at first sight appear an attractive bandwagon to jump onto. But, especially in the case of drylands already experiencing degradation, additional demands may drive the eco-system to unsustainability. The way ahead might be best resolved based on an economic analysis, natural resource sustainability assessment and study of the effect on the livelihoods of the resource-poor, apart from the generally more cost/benefit types of analysis.

Finally, there are already several sustainable alternative energy sources to fossil fuels available and with some collective thinking more may be identified that do not 
compete with food security for the planet's human population. They deserve attention first.

$$
\begin{array}{r}
\text { Mahmoud Solh } \\
\text { Director General } \\
\text { International Center for Agricultural Research in } \\
\text { the Dry Areas (ICARDA) } \\
\text { Aleppo, Syrian Arab Republic }
\end{array}
$$

\author{
R. B. Hiremath \\ Research Scholar \\ $A E$ and CST, Indian Institute of Science \\ Bangalore, Karnataka, India, and \\ Bimlesh Kumar \\ Research Scholar, Civil Engineering \\ Indian Institute of Science \\ Bangalore, Karnataka, India
}

A large populous and developing country, such as India, must adopt an integrated strategy to meet growing food, fodder, fuel and timber requirements. The main reason is that these dominant biomass needs should not compete for land, given the high human and livestock population densities in India. Traditionally, fodder is a by-product of cereal crops, which account for $72 \%$ of the total cropped area (http://www.teriin.org). Based on the analysis made by Ravindranath and Chanakya (1986) and TERI (http:// www.teriin.org/), we summarize the arguments to show that land is not a constraint for bio-energy options. The area under crops has stabilized at around 140-143 Mha from 1970 to 2001 (shown below in Figure 1) and the degraded land estimates vary from 66 Mha to 130 Mha.

According to a projection by a working group established by the Planning Commission of India, the demand for food grains for a population of 1.3 billion is projected to be $270 \mathrm{Mt}$ by 2020 (http://www.vision2020india.org/). The projected food grain requirement of 270-300 Mt can be achieved by increasing the food grain yield from the current $1.64 \mathrm{t} / \mathrm{ha}$ in $2000-2001$ to $2.3 \mathrm{t} / \mathrm{ha}$ using the $127.5 \mathrm{Mha}$ (2001) of land currently under food grains. In fact, there is potential to at least double food grain productivity to the range of 3-4t/ha with expansion of irrigation, multiple cropping and modern cultivation practices. Thus, it is possible to meet the food grain requirement of the growing population without increasing the cropped area.

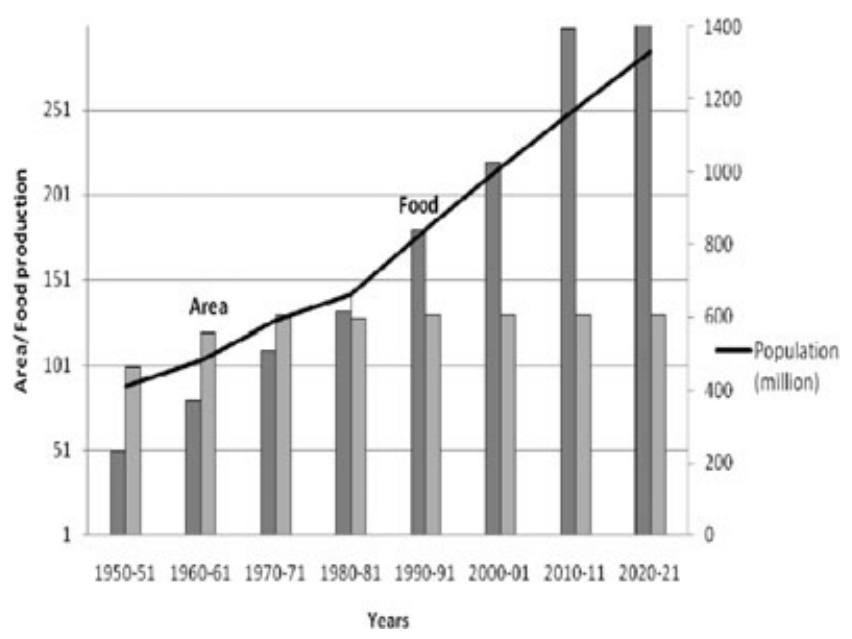

Figure 1. Growth in population, area under crops and food production, area in Mha, food production in Mt.

\section{Reference:}

Ravindranath, N.H., Chanakya, H.N., 1986. Biomass based energy system for a South Indian village. Biomass, 9: 215-233.

The growing demand for renewable energy sources would probably not be addressed by traditional agriculture and current technologies in biodiesel or ethanol without threatening food security. The actual productivity of oil and saccharides crops would demand large hectares of arable land to produce enough raw materials for the biofuel industry. Therefore, it would compromise food production. The development of technologies for intensive growing of algae or fungi using sludge or other wastes as nutrients would not only address the oils and sugars requirements but would also eliminate environmental passives.

On the other hand, the current technologies in place to produce biodiesel or ethanol demand high quality starting materials. The challenge is to develop new technologies using all available wastes from industrial, agricultural and human activities, as well as low quality feed stocks such as algae oils. Nowadays humanity is using just one solution for liquid fuels. In the future, this comfortable situation may not be available. The future will be a kaleidoscope of different fuels and technologies. Different industrial processes, such as pyrolysis and Fischer-Tropchs BTL, will become more suitable to produce fuels from low cost and highly available raw materials than transesterification of high quality oils or fermentation of edible sugars.

Paulo A. Z. Suarez Laboratório de Materiais e Combustiveis Institute de Química Universidade de Brasília, Brazil

The threat to food security, although clear and present, is not, however, beyond control. The threat would be manageable if the world community entered into proper and meaningful cooperation in favour of enhancing global understanding in the areas of food grains reserve creation, maintenance and replenishment, encouraging and facilitating inter-regional, intra-regional and intercontinental pooling of resources (including power pooling) that help alleviate the problem of growing energy demand. 
In parallel, investment in the agricultural sector would need to be increased with substantial focus on research and development.

To facilitate global cooperation, a number of human rights instruments and supporting documents, with their built-in dynamism, can be useful, since there is an abundance of scholars now who already consider the right to food a human right. Therefore, the international community needs to unite and prepare an international legal framework to establish an institution (or a mechanism) to ensure, through hard as well as soft law, full-fledged cooperation in this area. This cooperation should not only be amongst national governments, but also amongst other non-state public and private actors. In parallel, reform of legal and institutional frameworks in countries, along with policies to regulate scarce resource allocations through taxes and other means, should be encouraged.

Dr. Kishor Uprety
International Lawyer
Washington DC, USA

Promotion of biofuel production induced by its growing demand will certainly have an inverse relationship with food security unless caution is exercised. The concept of food security, which originated in the mid 1970s, was further defined at the 1996 World Food Summit as "a situation that exists when all people at all times, have physical, social and economic access to sufficient, safe and nutritious food to meet their dietary needs and food preferences for an active and healthy life". Food security problems are rampant globally and nationally. They are: natural disasters, a large global expanse of arable, agriculturally disadvantaged lands; and economic collapse. Conflicts, such as wars, are further exacerbated by the conversion of inadequate arable crops such as maize and sugarcane for food to biofuel. This translates to colossal loss of employment in food industries and carbon hydrate as energy given food to feed animals and man.

Unlike fossil fuel, biofuel is derived from relatively recent dead biological materials. Apart from its unhealthy competition with food production, it is also unhealthy for human existence when combusted because its fire sly contributes to global warming, air, water and land pollution.

The caution required is to limit the production of biofuel using biological resources with low competition as compared to conventional food crops that require prime land. The plants that have the ability to grow wild and rehabilitate degraded land such as Jatropha curca suffice, lifting underground water for clean energy resources such as solar, electricity and wind for lighting, cars, buses and trains, to mention but a few.

\section{Dr. Marufdeen Adekunle Abdulrahim Department of Geography Usmanu Danfodiyo University Sokoto, Nigeria}

\section{Biofuels and trees in humid tropical countries of West Africa}

In the humid tropics, with rich tree crops such as cocoa and abundant staples such as cassava, is there any place for biofuels? Using staple and annual crops as biofuels is dangerous for food security. However, to exploit trees/ perennial crops along with the capacity of the tropics to generate rapid growth of perennials for the production of biofuels would be logical.

As an integral part of an improved slash-and-burn system, they could contribute to food security. In West Africa, the dominant tree crop - cocoa - often competes with food crops at the mature stage of the cocoa farm but does not do so at the two ends of the farm life cycle. At the young stage, the tree is intercropped with a number of different food crops. When the 'perennial' dies, food crops reappear. This cycle can be managed and adapted to 'perennials' such as oil palm and Jatropha, and also accompany social change.

The driving forces of oil palm cultivation are that replanting cocoa on degraded land is difficult and farmers like to maintain a tree cover on their land as a property marker. Market diversification of palm oil to include biofuels may support this strategy. As a shrub that can be grown on degraded land, Jatropha is also emerging at just the right time.

François Ruf

Agricultural Economist

French Agricultural Research Centre for International Development (CIRAD)

UMR Innovation, and Jean-Claude Legoupil Agronomis,

Forum for Agricultural Research in Africa (FARA) and French Agricultural Research Centre for International Development (CIRAD) 